\title{
The Importance of a Great Finish
}

\section{YOU HAVE TO FINISH STRONG, EVERY TIME.}

\section{KATE MATSUDAIRA}

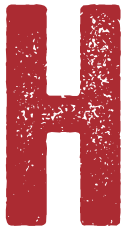

ave you ever felt super excited about the start of a project, but as time went on your excitement [and motivation] started to wane?

Unfortunately, not all work is created equal.

It is often the work through the bulk of a project that is not remembered or recognized.

The work that tends to be remembered from any given project is the work that happened last. It is the final step that most people will think of, because it happened most recently. This is especially true of the people who have the most power over your promotions and future opportunities, who don't see what you accomplish day to day. They just see the results.

I have worked with hundreds of engineers during my career, and I have seen this happen over and over again. Projects start with a bang and end with a whimper, and the people on the team are surprised when their hard work isn't viewed as positively as they think it should be.

How can you make sure that you are recognized as a valuable member of your team, whose work is seen as critical to the team's success?

You have to finish

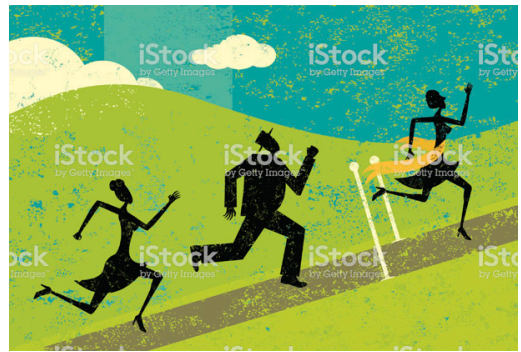


strong, every time. Here is how to keep your momentum up and make the right moves to be a visible contributor to the final success of every project.

\section{THE PSYCHOLOGY OF A STRONG FINISH}

Humans tend to remember the ending of a thing far more clearly than any other part-even if other parts were more significant or important. Why is that?

Essentially, our brains can process only so much. We take in so much information every day that it is impossible to remember everything completely. As a result, our brains have to give priority to certain pieces of information over others.

This means that we usually have the clearest recall for things that were associated with strong emotions and things that happened most recently. This is known as the Peak-End Rule.

This applies to all areas of our lives. It's why you should always stay at the nicest hotel at the very end of your vacation-it's the one you will remember most when you think about that trip.

At work, your performance reviews are usually weighted toward the work you did most recently. Why? Because it is freshest in your manager's mind.

So, when you are working on a project, think about how it will be perceived by your leadership, keeping in mind the importance of the end result.

While you might remember the long hours you worked to build a new feature one night, your boss may have a different perspective. If, for example, that feature you built had bugs that had to be fixed at the last minute, or 


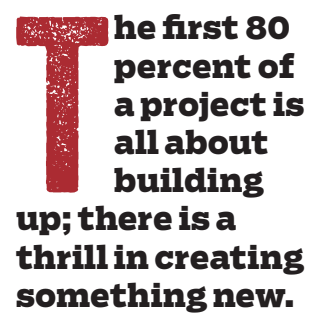

operational problems that generated negative attention, that's what the boss will remember more than the many hours you put in.

Therefore, if you want to make a big impact at work, you need to take advantage of the Peak-End Rule by ensuring that every project you work on has a successful, strong conclusion. If you are in a position to present the project to your leadership, make sure they see how your hard work applies to their goals and the things that are most important to them.

\section{WHY SO FEW PEOPLE FINISH STRONG}

Starting work on a new project or goal is usually an exciting time. In the beginning, there is a lot of momentum. You are excited to tackle a big problem, and energy is high in meetings. The first 80 percent of a project is all about building up; there is a thrill in creating something new.

By the end, though, energy is low. You push to get things done by a deadline, and you procrastinate on the boring stuff that still has to get done, like extra testing, polishing, documentation, and boundary cases you missed earlier.

The less elegant work isn't as much fun to work on, so people don't really work on it. Plus, there's very little recognition for this kind of work.

Our brains are resistant to working on tasks that don't seem to offer some kind of reward. They seem too small, or too tedious. It can be mentally, and even physically, taxing to spend time on a job that you don't want to do or know you won't be directly rewarded for.

These mundane tasks, when done correctly, make the problems they are solving invisible. You would only ever 
notice if that work hadn't been done because you would have a buggy, clunky product. When the details are done right, it looks seamless and you forget about how much work went into finishing.

Unfortunately, letting these boring details go is akin to undoing all the exciting work you already put in on the project. If you want the beautiful thing you built to stay standing, you have to finish it out right.

\section{HOW TO MAKE A GREAT FINISH A PRIORITY}

The next time you are hard at work on a big project, make sure you allot time and energy for a strong finish. Set aside time in your project plans for the boring detail work; that way, it won't catch you by surprise. Make it seem just as important as all the rest of the work you do-because it is.

As you get to work on your next big goal, keep in mind these three ways to make sure you finish strong and make the biggest possible impact with your work.

\section{Think big picture}

-When you are working on a project, always keep the bigger-picture goals in mind. What is the overall impact of this project on your company? What does your manager see as your team's biggest goal?

You may remember an amazing solution you came up with early in the project, but your manager or executive team-who weren't in the trenches with you every day, and who instead are making judgments based on limited information channeled up to them-have only so many details to go on. One of the biggest factors they use to determine success or failure is how a project wrapped up. 
Did the project miss the deadline? Were there tons of bugs reported right after the launch? Did your team have to explain to the boss why $x, y, z$ didn't work?

Whenever you are choosing what to work on or where to apply your best efforts, take a moment to step back. Zoom out from your own preferences and remind yourself what the bigger-picture goals are. Where will your work mean the most to the people in charge?

If you're not sure, ask. Go to your manager and say, "I am thinking about working on A or B next. Which is most important? Or is there another place I should be focusing?"

It may seem counterintuitive-you might worry that asking about priorities might make you look stupid-but checking in with your manager is actually really smart. Not only do you ensure you are working on the right priorities, but it is also a great way to keep your manager up to date about your contributions and show that you are focused on the big-picture goals that matter most to managers.

\section{2}

Make the unglamorous a priority

When people lose momentum on a project, it is usually right around the time that the shiniest, most interesting work gets completed. Don't let this happen to you.

One way to approach the boring details of a projectbug fixes, use cases, etc.-is to reframe them in your mind. Tell yourself that this is actually some of the most important work you'll do because you will be helping the outcome to be as perfect as it can be.

Look for opportunities to make these tasks more challenging or interesting. Instead of slogging through boring details, try to bring new energy to them. 
Although this work may not be all that visible, it is still important. Remember that a rising tide lifts all boats. Even if you don't get the glory for fixing small final details, your work will make the overall project more successful in the end, and you will have been part of a team that executed well. In time, you will become known for always being on the team that succeeds.

\section{Related articles}

$\Rightarrow$ The Small Batches Principle

Reducing waste, encouraging experimentation, and making everyone happy Thomas A. Limoncelli https://queue.acm.org/detail.cfm?id=2945077

$\Rightarrow$ Kode Vicious Unleashed

A koder with attitude, KV answers your questions. Miss Manners he ain't. https://queue.acm.org/detail.cfm?id=1046939 $\Rightarrow$ Culture Surprises in Remote Software Development Teams Judith S. Olson, Gary M. Olson "When in Rome" doesn't help when your team crosses time zonesand your deadline doesn't.

https://queue.acm.org/detail.cfm?id=966804

\section{Channel your ability J.to keep going} Have you ever heard a story about a mother who lifted a car to save her child? What about marathon runners who talk about having "nothing left" but go on to finish the race?

We all have extreme strength within us; we just don't usually see it because it comes out only in extreme circumstances.

In normal life, your brain communicates with your body about what you can and cannot do. Your brain

says, "Hey, that will hurt," and your body slows down. In most situations, this serves you well. You can't actually lift a car every day, and you wouldn't want to try.

However, the ability to power through challenges that you normally don't face is in your toolkit. Remember that 
the next time you are nearing the end of a long, exhausting project. You can do it. You might feel like you have nothing left, but the end is the most important part-so, draw on your resources and make the last steps count.

If you work hard on a project, your hours won't be worth as much if you aren't seen delivering a strong finish. So, make all that work worth it, and follow through on every single step. Dot your i's, cross your t's, and deliver amazing results that will take you far in your career.

Kate Matsudaira is an experienced technology leader. She worked in big companies such as Microsoft and Amazon and three successful startups (Decide acquired by eBay, Moz, and Delve Networks acquired by Limelight] before starting her own company, Popforms (https://popforms.com/l, which was acquired by Safari Books. Having spent her early career as a software engineer, she is deeply technical and has done leading work on distributed systems, cloud computing, and mobile. She has experience managing entire product teams and research scientists and has built her own profitable business. She is a published author, keynote speaker, and has been honored with awards such as Seattle's Top 40 under 40. She sits on the board of acmqueue and maintains a personal blog at katemats.com.

Copyright $\odot 2018$ held by ownerlauthor. Publication rights licensed to ACM. 